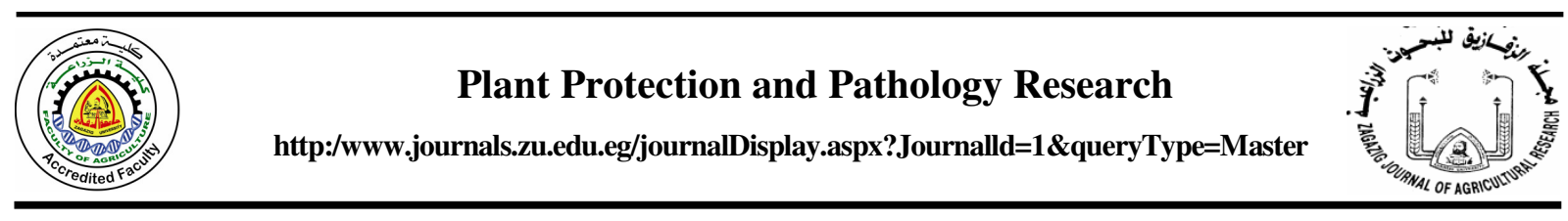

\title{
FACTORS AFFECTING ACCEPTANCE AND MATING SUCCESS OF HONEYBEE VIRGIN QUEENS, Apis mellifera $\mathrm{L}$.
}

\author{
Mohamed A. Khattaby ${ }^{2 *}$, S.I .Yousif ${ }^{1}$, Walaa M.M. Helaly ${ }^{1}$ and R.E. Sanad ${ }^{2}$ \\ 1. Pl. Prot. Dept., Fac. Agric., Zagazig Univ., Egypt \\ 2. Pl. Prot. Res. Inst., ARC, Egypt
}

Received: 23/04/2018 ; Accepted: 24/06/2018

\begin{abstract}
The present work was carried out to study the effect of four introduction cycles (February, March, April, May) of F1 Carniolan and F1 Italian virgin queens introduced on 3- and 5comb mating nuclei of the same and inverse subspecies (genotype) on virgin acceptance and mating success. The experiments were made in a private apiary located at Zagazig District, Sharkia Governorate, Egypt during 2016 and 2017 seasons. Results revealed that virgin acceptance rates for both F1 Carniolan and F1 Italian virgins were relatively higher in February and March introduction cycles, recording between 90.0-100.0\% acceptances in the two seasons. The least acceptance rates were exhibited in April introduction cycle for both hybrids, meanwhile the least mating success was recorded for May cycle in the two seasons. The rate of acceptance was relatively similar in both 3-and 5 -comb mating nuclei. Meanwhile, mating success of virgins of both subspecies was relatively higher in the stronger mating nuclei (5-comb nuclei). Introducing virgin queens in mating nuclei of the inverse genotype, showed varied acceptance and mating success values between the two virgin genotypes, where F1 Carniolan virgin queens introduced on 5-comb F1 Italian mating nuclei showed means of 77.5 and $80.0 \%$ acceptances, meanwhile F1 Italian virgins introduced on 5-comb F1 Carniolan mating nuclei recorded means of 82.5 and $85.0 \%$ acceptances when introduced on $\mathrm{F} 1$ Carniolan mating nuclei in the two seasons, respectively. In addition, mean mating success rate was relatively higher for F1 Italian queens introduced on 5-comb F1 Carniolan mating nuclei that recorded 96.88 and $94.10 \%$ compared to 85.07 and $84.28 \%$ for F1 Carniolan queens mated in F1 Italian nuclei in both seasons, respectively.
\end{abstract}

Key words: Apis mellifera L., mating success, virgin queen, $\mathrm{F}_{1}$ Italian hybrid, F1 Carniolan hybrid, queen acceptance, nectar flow, aggressiveness.

\section{INTRODUCTION}

Honeybee queen is the mother of the colony, being responsible for producing the offspring of workers and drones. Another main job of the queen, is the production (secretion) of queen substance (pheromones), that highly requested for the stability of the colony as a social community, inhibiting workers ovary development to prevent the appearance of egg laying workers and to prevent queen rearing and replacement.

The higher rate of oviposition of the queen resulted in the rapid depletion of sperms stored

* Corresponding author: Tel. : +201002143188

E-mail address: m_khattaby9111@yahoo.com in queen's spermatheca. So, the queen laid more unfertilized eggs that developed into drones which lead to decrease the population of workers and decreased the secreted amount of queen substance by the old queen. Unless the beekeeper interferes to replace the old queen, the colony starts to supersede the old queen. Therefore, beekeepers tend to replace old queen periodically by another new mated or virgin one.

Introduction of new queen to mating nuclei or normal colony always faces by rejection (to any foreign individual) that represented by balling of the workers on the new queen to kill her. Many factors are responsible for this 
aggressive temper (behavior) towards the new queens. Ruttner (1983) attributed the acceptance or rejection of the new queen to multiple factors, i.e., characteristics of the introduced queen (weight, age, race and production of pheromones). Moreover, characteristics of the receiver colony (race, aggressiveness, seasonal development and ratio of young to old workers) and the external conditions (nectar flow, climate and season) (Azevedo, 2007).

Mating success of the virgin queens is governed (controlled) by many factors including climatic variables, (Jung, 1981), weight of virgin at emergence (El-Dessouki et al., 2005; Akyol et al., 2007), the presence of brood (especially sealed ones) (Hassan et al., 2004), age of workers of mating nuclei and season of the year (Moretto et al., 2004; Koc and Karacaoglu, 2016), nectar flow season and absence of wasps and bee eaters (Omar $\boldsymbol{e t}$ al., 2004) and drone rearing cycle (Ruttner, 1964).

Therefore, the present work was designed to study the effect of four introduction cycles (February, March, April and May) of F1 Carniolan and F1 Italian virgin queens introduced on 3and 5-comb mating nuclei of the same and inverse subspecies (genotype) on virgin acceptance and mating success.

\section{MATERIALS AND METHODS}

The present investigations were carried out to study the effect of some factors on honeybee queen acceptance, mating and prolificacy during the period extended from 2016-2017. Field experiments were performed in a private apiary located at Zagazig District, Sharkia Governorate, Egypt.

\section{Honeybee Colonies}

The apiaries selected were chosen to contain both F1 Carniolan Apis mellifera carinca and F1 Italian, $A$. m. ligustica hybrid colonies in sufficient numbers (at least 40 colonies of each hybrid).

Queen acceptance was tested in four successive months; i.e. February, March, April and May in 2016 and 2017 seasons. In each month, 40 nuclei were initiated for each hybrid as follows:
- Twenty 3-comb nuclei that were divided into 2 groups, 10 nuclei each of both F1 Carniolan and F1 Italian colonies.

- Twenty 5-comb nuclei that were divided into 2 groups, 10 nuclei each of the two tested hybrids.

Initiation of test nuclei was made by division of strong colonies of both hybrids. All the produced nuclei were queenless. Each nucleus was composed of 2 brood combs (one open "unsealed" and one sealed) and a honey comb for 3-comb nuclei. Meanwhile, 5-comb nuclei were composed of 3 brood combs ( 1 open and two sealed brood combs) and two honey combs. All combs were covered with bees from both sides.

For both nuclei strength, the bees covering honey combs, mostly field bees were discarded in the mother colony, instead bees covering the same number of brood combs (nurse bees) were discarded in the initiating nucleus to assure good acceptance.

Virgin queens were introduced on the second day after division process had been performed to insure good acceptance and mating.

All nuclei in each group were equalized, as possible, in strength, brood, stored honey and bee bread during initiation process.

In each month, sisters of $\mathrm{F} 1$ Carniolan and $\mathrm{F} 1$ Italian virgin queens were obtained from Honeybee Department, Plant Protection Research Institute, Dokki, Giza, Egypt. Virgins were always two days old on the day of introduction.

Virgins of each hybrid were introduced on both hybrid nuclei of both strengths, i.e. in each month, ten sisters of F1 Carniolan virgins were introduced individually in both Carniolan and Italian initiated 3- and 5-comb nuclei.

Initiated nuclei and mother colonies were fed periodically on sucrose syrup $(1: 1)$ and $(2: 1)$ sugar : water according to weather variables. Pollen substitute patties were also offered to encourage rapid growth of the colonies.

The introduced virgins were followed up to acceptance, mating and egg laying. The following parameters were recorded: 
1- The number of accepted virgins in each group and the percentage of acceptance were calculated according the following equation:

Acceptance $(\%)=$

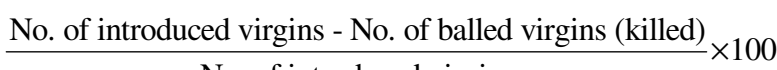
No. of introduced virgins

2- Number of mated queens in each group and percentage of mating success were performed following the above-mentioned equation.

\section{RESULTS AND DISCUSSION}

\section{Virgin Queens Acceptance and Mating Success}

Ten virgins from both F1 Carniolan and F1 Italian hybrid bees were introduced on two mating nuclei strengths, i.e. 3- and 5-comb nuclei of both hybrids. Four introduction cycles were considered at the rate of one cycle per month (February, March, April and May) in 2016 and 2017. The virgins introduction was achieved (performed) twice, in the first the virgins were introduced on mating nuclei of the same queen genotype (hybrid), whereas in the second the virgins were introduced on mating nuclei of the inverse genotype. The rates of virgin acceptance as well as mating success were evaluated.

\section{Virgins Acceptance in Mating Nuclei of the Same and Inverse Genotypes}

In case of mating nuclei of the same genotype results in Table 1 indicate that the percentage of F1 Carniolan virgins acceptance attained $90,100,80$ and $80 \%$ as well as 90,90 , 90 and $80 \%$ for the virgins introduced on 3comb F1 Carniolan mating nuclei and 100, 90, 80 and $90 \%$ as well as $100,100,90$ and $70 \%$ for those introduced on 5-comb $\mathrm{F}_{1}$ Carniolan mating nuclei during February, March, April and May introduction cycles with the same mean percentages of 87.5 and $90.0 \%$ in 2016 and 2017 seasons, respectively.

Regarding acceptance percentage of F1 Italian virgins, results in Table 1 show that these percentages recorded $90,100,80$ and $80 \%$ as well as $90,100,90$ and $80 \%$ when the virgins were introduced on 3-comb mating nuclei, and $100,100,90$ and $80 \%$ as well as 100, 100, 80 and $70 \%$ for those introduced on 5-comb F1
Italian mating nuclei in the four introduction cycles with the mean percentages of 87.5, 90.0, 92.5 and $87.5 \%$ in 2016 and 2017 seasons, respectively.

Concerning the virgins acceptance in inverse genotype mating nuclei, the first hybrid Carniolan virgins were introduced in F1 Italian 3- and 5-comb mating nuclei and the inverse was also made during introduction cycles i.e. February, March, April and May of 2016 and 2017. The results presented in Table 1 clear also that acceptance percentage of F1 Carniolan virgins introduced in 3-comb F1 Italian mating nuclei recorded $80,80,80$ and $70 \%$ as well as $80,80,70$ and $80 \%$ with the mean percentages of the same number $(77.5 \%)$ in the two seasons and in 5-comb F1 Italian nuclei were 80, 90, 60 and $80 \%$ as well as $80,90,70$ and $80 \%$ in the four introduction cycles in the two seasons with the mean percentages of 77.5 and $80.0 \%$, respectively.

Virgin acceptance is relatively higher when mating nuclei were stronger (5-comb nuclei) as compared to that recorded for 3-comb mating nuclei of both hybrids. The same conclusion was also reported by Omar et al. (2004) who stated that mating nuclei strength had positive effect on acceptance of virgin queens.

Generally, acceptance percentage was noticeably higher during February and March cycles. On the contrary, the least mating rate of virgins of both hybrids was recorded during April cycle followed by May cycle in both seasons. In connection, Moretto et al. (2004) and Al-Ghazawi and Zaitoun (2008) stated that the season of the year and queens genotype (origin) had the greatest effect on queens acceptance. Also Koc and Karacaoglu (2016) in Turkey recorded the highest queen acceptance in March and April, sure the conditions are varied.

\section{Mating Success of Virgin Queens Introduced on Mating Nuclei of the Same and Inverse Genotypes}

Rate of mating of F1 Carniolan and F1 Italian virgin queens when introduced on 3- and 5 -comb mating nuclei of the same and the inverse genotypes of virgins was evaluated during 4 introductions cycles of virgins, i.e. February, March, April and May of 2016 and 2017 seasons (Table 2 ). 
Table 1. Percentages of acceptance of F1 Carinolan and F1 Italian virgins introduced on 3- and 5-comb mating nuclei of the same and inverse genotype during four introducing cycles in 2016 and 2017 seasons (No. of introduced virgins $=10$ virgins/cycle)

\begin{tabular}{|c|c|c|c|c|c|c|c|c|}
\hline \multirow{2}{*}{$\begin{array}{l}\text { Virgin genotype } \\
\text { Nucleus genotype } \\
\text { and strength } \\
\text { Introduction cycle }\end{array}$} & \multicolumn{4}{|c|}{$F_{1}$ Carinolan virgin } & \multicolumn{4}{|c|}{$F_{1}$ Italian virgin } \\
\hline & $\begin{array}{c}\text { 3-comb. } \\
\text { F1 } \\
\text { Carniolan } \\
\text { nucleus }\end{array}$ & $\begin{array}{c}\text { 5-comb. } \\
\text { F1 } \\
\text { Carniolan } \\
\text { nucleus }\end{array}$ & $\begin{array}{c}\text { 3-comb. } \\
\text { F1 } \\
\text { Italian } \\
\text { nucleus }\end{array}$ & $\begin{array}{c}\text { 5-comb. } \\
\text { F1 } \\
\text { Italian } \\
\text { nucleus } \\
\end{array}$ & $\begin{array}{l}\text { 3-comb. } \\
\text { F1 } \\
\text { Italian } \\
\text { nucleus }\end{array}$ & $\begin{array}{c}\text { 5-comb. } \\
\text { F1 } \\
\text { Italian } \\
\text { nucleus } \\
\end{array}$ & $\begin{array}{c}\text { 3-comb. } \\
\text { F1 } \\
\text { Carniola } \\
\text { n nucleus }\end{array}$ & $\begin{array}{c}\text { 5-comb. } \\
\text { F1 } \\
\text { Carniolan } \\
\text { nucleus }\end{array}$ \\
\hline & \multicolumn{8}{|c|}{2016 season } \\
\hline February & 90.0 & 100.0 & 80.0 & 80.0 & 90.0 & 100.0 & 90.0 & 90.0 \\
\hline March & 100.0 & 90.0 & 80.0 & 90.0 & 100.0 & 100.0 & 90.0 & 80.0 \\
\hline April & 80.0 & 80.0 & 80.0 & 60.0 & 80.0 & 90.0 & 80.0 & 80.0 \\
\hline May & 80.0 & 90.0 & 70.0 & 80.0 & 80.0 & 80.0 & 70.0 & 80.0 \\
\hline \multirow[t]{2}{*}{ Mean } & 87.5 & 90.0 & 77.5 & 77.5 & 87.5 & 92.5 & 82.5 & 82.5 \\
\hline & \multicolumn{8}{|c|}{2017 season } \\
\hline February & 90.0 & 100.0 & 80.0 & 80.0 & 90.0 & 100.0 & 90.0 & 90.0 \\
\hline March & 90.0 & 100.0 & 80.0 & 90.0 & 100.0 & 100.0 & 90.0 & 90.0 \\
\hline April & 90.0 & 90.0 & 70.0 & 70.0 & 90.0 & 80.0 & 80.0 & 80.0 \\
\hline May & 80.0 & 70.0 & 80.0 & 80.0 & 80.0 & 70.0 & 80.0 & 80.0 \\
\hline Mean & 87.5 & 90.0 & 77.5 & 80.0 & 90.0 & 87.5 & 85.0 & 85.0 \\
\hline
\end{tabular}

Table 2. Percentages of mating success of F1 Carinolan and F1 Italian virgins introduced on 3and 5-comb mating nuclei of the same and inverse genotype during four introducing cycles in 2016 and 2017 seasons (No. of introduced virgins=10 virgins/cycle)

\begin{tabular}{|c|c|c|c|c|c|c|c|c|}
\hline \multirow{2}{*}{$\begin{array}{l}\text { Virgin genotype } \\
\text { Nucleus genotype } \\
\text { and strength } \\
\text { Introduction cycle }\end{array}$} & \multicolumn{4}{|c|}{$F_{1}$ Carinolan virgins } & \multicolumn{4}{|c|}{$F_{1}$ Italian virgins } \\
\hline & $\begin{array}{c}\text { 3-comb. } \\
\text { F1 } \\
\text { Carniolan } \\
\text { nucleus } \\
\end{array}$ & $\begin{array}{c}\text { 5-comb. } \\
\text { F1 } \\
\text { Carniolan } \\
\text { nucleus } \\
\end{array}$ & $\begin{array}{l}\text { 3-comb. } \\
\text { F1 } \\
\text { Italian } \\
\text { nucleus } \\
\end{array}$ & $\begin{array}{c}\text { 5-comb. } \\
\text { F1 } \\
\text { Italian } \\
\text { nucleus } \\
\end{array}$ & $\begin{array}{c}\text { 3-comb. } \\
\text { F1 } \\
\text { Italian } \\
\text { nucleus } \\
\end{array}$ & $\begin{array}{c}\text { 5-comb. } \\
\text { F1 } \\
\text { Italian } \\
\text { nucleus } \\
\end{array}$ & $\begin{array}{c}\text { 3-comb. } \\
\text { F1 } \\
\text { Carniolan } \\
\text { nucleus } \\
\end{array}$ & $\begin{array}{c}\text { 5-comb. } \\
\text { F1 } \\
\text { Carniolan } \\
\text { nucleus } \\
\end{array}$ \\
\hline & \multicolumn{8}{|c|}{\begin{tabular}{|c|c|}
2016 season \\
\end{tabular}} \\
\hline February & 100.00 & 100.00 & 87.50 & 87.50 & 100.00 & 100.00 & 88.89 & 100.00 \\
\hline March & 90.00 & 100.00 & 75.00 & 77.78 & 100.00 & 100.00 & 100.00 & 100.00 \\
\hline April & 87.50 & 87.50 & 62.50 & 100.00 & 87.50 & 100.00 & 87.50 & 100.00 \\
\hline May & 87.50 & 88.89 & 85.71 & 75.00 & 75.00 & 75.00 & 71.43 & 87.50 \\
\hline \multirow[t]{2}{*}{ Mean } & 91.25 & 94.10 & 77.68 & 85.07 & 90.63 & 93.75 & 86.96 & 96.88 \\
\hline & \multicolumn{8}{|c|}{2017 season } \\
\hline February & 100.00 & 100.00 & 87.50 & 87.50 & 100.00 & 100.00 & 88.89 & 88.89 \\
\hline March & 88.89 & 90.00 & 75.00 & 88.89 & 100.00 & 90.00 & 100.00 & 100.00 \\
\hline April & 77.78 & 88.89 & 85.71 & 85.71 & 88.89 & 100.00 & 75.00 & 100.00 \\
\hline May & 75.00 & 85.71 & 87.50 & 75.00 & 75.00 & 71.43 & 87.50 & 87.50 \\
\hline Mean & 85.42 & 91.15 & 83.93 & 84.28 & 90.97 & 90.36 & 87.85 & 94.10 \\
\hline
\end{tabular}


For the virgin queens introduced on mating nuclei of the same genotype, results presented in Table 2 clear that mating success of F1 Carniolan virgins introduced on 3-comb mating nuclei of the same genotype recorded 100.00, $90.00,87.50$ and $87.50 \%$ in 2016 season, as well as $100.00,88.89,77.78$ and $75.00 \%$ in 2017 season for the virgins introduced during February, March, April and May, respectively. The mean percentage of mating success regardless of introduction months recorded $91.25 \%$ in 2016 season and $85.42 \%$ in the second season. Results of 5-comb mating nuclei manifested higher mating percentages. The percentages of virgins mating attainted 100.00, $100.00,87.50$ and $88.89 \%$ in 2016 season and $100.00,90.00,88.89$ and $85.71 \%$ in 2017 season in February, March, April and May introduction cycles with mean mating success of 94.10 and $91.15 \%$ in 2016 and 2017 seasons, respectively.

The virgins of the two hybrids showed relatively similar rate of mating success when virgins of the two subspecies were introduced on mating nuclei of the same subspecies. However, relatively higher mating success was noted for the virgins introduced on 5-comb nuclei than those introduced on 3-comb nuclei. The difference was more pronounced in case F1 Carniolan virgins where it was $94.10 \%$ compared to $91.25 \%$ in 2016 season and $91.15 \%$ by comparison with to $85.42 \%$ in 2017 season in 5-comb and 3-comb nuclei, respectively.

Virgin mating success is relatively higher when mating nuclei were stronger (5-comb nuclei) as compared to that recorded for 3-comb mating nuclei of both hybrids. The same conclusion was also reported by Hassan $\boldsymbol{e t}$ al. (2004) who stated that the existence of sealed brood in mating nuclei induced higher mating success of the queens as compared to unsealed brood. Omar et al. (2004) added that mating nuclei strength had positive effect on mating success of virgin queens. Koc and Karacaoglu (2016) in Turkey recorded the highest queen mating in March and April, sure the conditions are varied.

For Italian virgins the rate of virgin mating on 3-comb mating nuclei of the same subspecies recorded $100.00,100.00,87.50$ and $75.00 \%$ in 2016 as well as 100.00, 100.00, 88.89 and
$75.00 \%$ in 2017 season for the four introduction cycles, respectively with the mean mating success of $90.63 \%$ in 2016 and $90.97 \%$ in 2017 season. Introducing F1 Italian virgins on 5-comb F1 Italian mating nuclei realized 100.00, 100.00, 100.00 and $75.00 \%$ mating success in 2016 as well as 100.00, 90.00, 100.00 and 71.43 in 2017 for February, March, April and May introduction cycles, respectively with the mean mating success regardless of introduction cycles of $93.75 \%$ in 2016 and $90.36 \%$ in 2017.

In case of F1 Carniolan virgins introduced on F1 Italian mating nuclei, results presented in Table 2 show that the rate of mating success of F1 Carniolan virgins introduced on 3-comb F1 Italian mating nuclei during February, March, April and May reached 87.50, 75.00, 62.50 and $85.71 \%$ as well as $87.50,75.00,85.71$ and $87.50 \%$ in the two seasons, successively. The mean seasonal percentage of virgins mating regardless of introduction cycles attained $77.68 \%$ in 2016 season and $83.93 \%$ in 2017 season.

The picture in case of introducing $\mathrm{F} 1$ Carniolan virgins on 5-comb F1 Italian mating nuclei was slightly different (higher). For instance, the percentage of mating success recorded $87.50,77.78,100.00$ and $75.00 \%$ in 2016 season as well as $87.50,88.89,85.71$ and $75.00 \%$ in 2017 season for February, March, April and May, introduction cycles, respectively. The mean percentage of mating of virgins regardless of the introduction cycles reached $85.07 \%$ in 2016 season and $84.28 \%$ in 2017 season.

Concerning F1 Italian virgins introduced on F1 Carniolan mating nuclei, the obtained results cleared that the mean percentage of mating of F1 Italian virgins introduced on 3-comb F1 Carniolan mating nuclei attained 88.89, 100.00, 87.50 and $71.43 \%$ as well as $88.89,100.00$, 75.00 and $87.50 \%$ in 2016 and 2017 seasons for February, March, April and May introduction cycles, respectively (Table 2). The mean seasonal percentage of mating of virgins regardless of introduction cycles was nearly similar recording 86.96 and $87.85 \%$ in 2016 and 2017 seasons, respectively.

A higher percentage of mating success was recorded when introducing F1 Italian virgins on 5-comb F1 Carniolan nuclei. For instance, the mating success attained 100.00, 100.00, 100.00 
and $87.50 \%$ in 2016 as well as $88.89,100.00$, 100.00 and $87.50 \%$ in 2017 for February, March, April and May introduction cycles, respectively (Table 2 ). The mean percentage of virgins mating regardless of introduction cycles recorded $96.88 \%$ in 2016 season and $94.10 \%$ in 2017 season, respectively.

Generally, it could be concluded that there was higher percentage of mating success that was recorded when virgin queens were introduced in mating nuclei of the same subspecies (genotype) of the virgin. This phenomenon was recorded for both honeybee hybrids in the two seasons of the study. Introducing virgin queens on mating nuclei of inverse subspecies (genotype) reduced the mating success, especially when F1 Carniolan virgins were introduced on F1 Italian mating nuclei.

It is obvious that introducing virgins of $\mathrm{F} 1$ Carniolan on F1 Italian nuclei manifests lower mating success, reflecting the rejection of $\mathrm{F} 1$ Italian bees to $\mathrm{F} 1$ Carniolan virgins (aggressiveness against foreign virgins). This statement is partially supported by that of Abd El-Wahab and Nour (2014). On the contrary, it doesn't matter for F1 Italian virgins introduced on F1 Carniolan mating nuclei, where mating success was higher, reflecting the docility of Carniolan bees towards foreign virgins in addition to the rapid motion (movement) of Italian virgins that enable them to escape from balling of workers. Racial variation in percentage of mating success was also reported by many authors. For instance, Hassan et al. (2004), Abd-El-Rahman (2006) and AlGhazawi and Zaitoun (2008) who reported the superiority of Italian queens over the other races in the percentage of mating.

\section{REFERENCES}

Abd El-Wahab, T.E. and M.E. Nour (2014). The role of the Egyptian honey bee workers in selecting adult queen kinships, and the impact on the colony's biological activities. Int. J. Agric. Technol., 10 (5): 1249-1259.

Abd-El-Rahman, Y.A. (2006). Studies on natural mating of honeybee queens in Upper Egypt. M.Sc. Thesis, Fac. Agric., Menia Univ., Egypt.
Akyol, E., H. Yeninar and O. Kaftanoglu (2007). Live weight of queen honey bees (Apis mellifera L.) predicts reproductive characteristics. J. Kansas Entomol. Soc., 81 (2): $92-100$

Al-Ghazawi, A.A. and S. Zaitoun (2008). Origin and rearing season of honeybee queens affect some of their physiological and reproductive characteristics. Entomol. Res., 38 (2): 139-148.

Azevedo, D. De-O., E.W. Teixerira, M.L.T.M.F. Alves, A.C.C.C. Moreti, B. Blochtein, J.C. Zanuncio and J.E. Serrao (2007). Comparative analyses of the abdominal tergal glands in Apis mellifera (Hymenoptera: Apidae) queens. Anim. Biol., 57 (3): 329 - 338.

El-Dessouki, S.A., I.S. Eissa, A.S. El-Khouly and G.F. Abo-Laban (2005). Effect of different grafting methods on some important characteristics and mating success of Carniolan F1 hybrid queens of honeybee. Ann. Agric. Sci., Moshtohor, 43 (4) : 19731980.

Hassan, A.R., A.M.M. Mazeed and E.E. Tharwat (2004). Effect of genotype, weight of honeybee virgin queens and brood status on some parameters used for judging the queens from their introduction until egglaying. Bulletin Fac. Agric., Cairo Univ., 55 (1): 37-55

Jung, G. (1981): Climate and mating. Bienevater, 120 (3): 71-74.

Koc, A.U.and M. Karacaoglu (2016). Overwintering of honey bee queens (Apis mellifera) by different methods under Aegean region conditions. Tarim Bilimleri Dergisi, 22 (2): 229-236.

Moretto, G., J.C.V. Guerra, H. Kalvelage and E. Espindola (2004). Maternal influence on the acceptance of virgin queens introduced into Africanized honey bee (Apis mellifera) colonies. Genet. and Molec. Res., 3 (3): 441445.

Omar, M.S., N.S.M. Omran and E.E. Haggag (2004). Increasing efficiency of queen introducing and mating success in (Apis mellifera carnica), under isolated conditions in New Valley- Egypt. Assiut J. Agric. Sci., 35 (4) : 67- 81. 
Ruttner, F. (1964). How much to we know about the mating of the queen bee? Sucwest deutscher Imker, 16 (3): 78-83.
Ruttner, H. (1983). Transport and introduction. In: Queen Rearing (Ed. Ruttner F.) Apimondia Publ. House, Bucharest, 279-294.

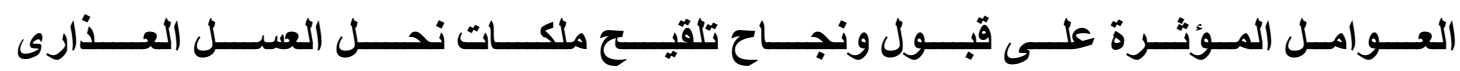

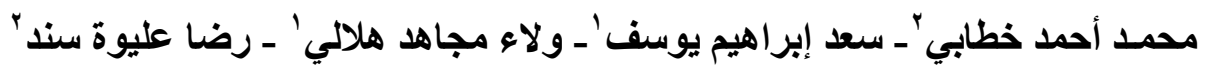

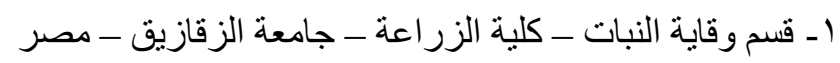

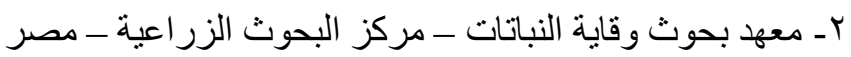

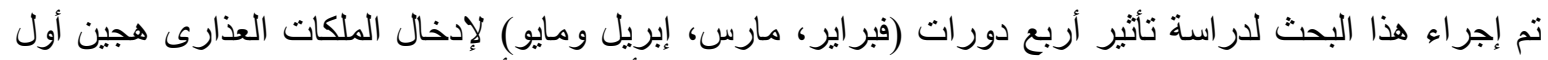

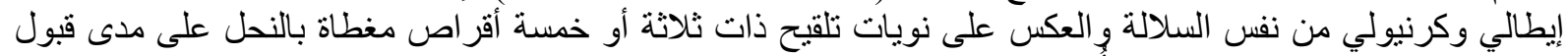

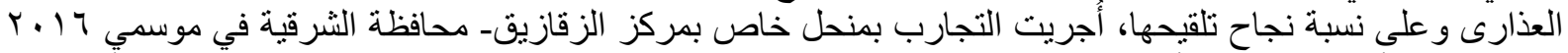

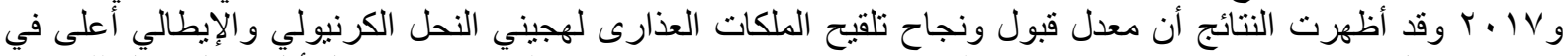

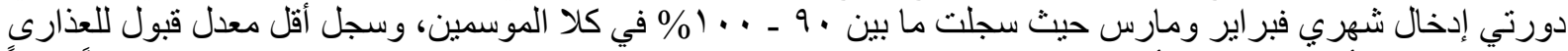

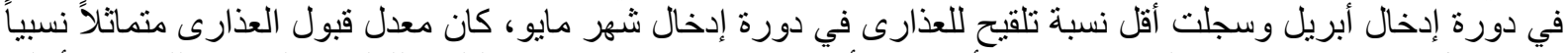

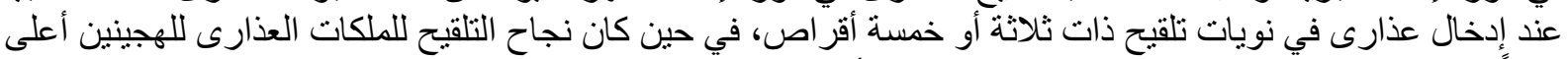

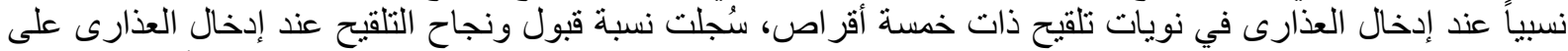

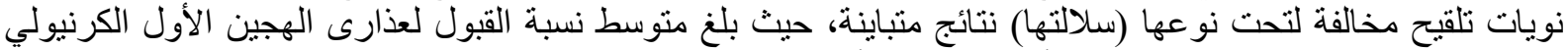

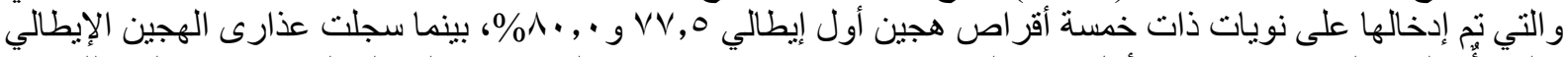

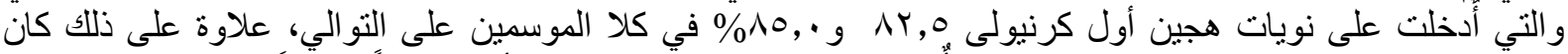

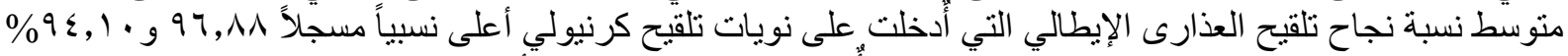

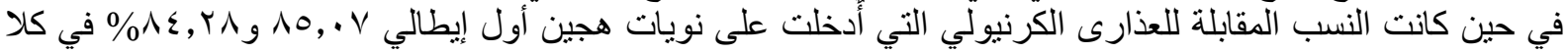

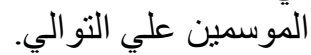

